NASA Technical Memorandum 102813

\title{
Small-Scale Experiments in STOVL Ground Effects
}

Victor R. Corsiglia and Douglas A. Wardwell, Ames Research Center, Moffett Field, California

Richard E. Kuhn, STO-VL Technology, San Diego, California

April 1991

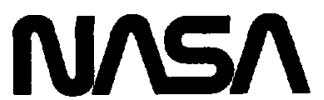

National Aeronautics and

Space Administration

Ames Research Center

Moffett Field, California 94035-1000 



\author{
Victor R. Corsiglia and Douglas A. Wardwell \\ NASA Ames Research Center \\ Moffett Field, Califomia, 94035 USA \\ Richard E. Kuhn \\ STO-VL Technology \\ San Diego, Califomia, 92128 USA
}

\begin{abstract}
A series of tests has been completed in which suckdown and fountain forces and pressures were measured on circular plates and twin-tandem-jet generic STOVL (short takeoff and vertical landing) configurations. The tests were conducted using a small-scale hover rig, for jet pressure ratios up to 6 and jet temperatures up to $700^{\circ} \mathrm{F}$. The measured suckdown force on a circular plate with a central jet was greater than that found with a commonly used empirical prediction method. The present data showed better agreement with other sets of data. The tests of the generic STOVL configurations were conducted to provide force and pressure data with a parametric variation of parameters so that an empirical prediction method could be developed. The effects of jet pressure ratio and temperature were found to be small. Lift improvement devices were shown to substantially reduce the net suckdown forces.
\end{abstract}

\section{Nomenclature}
A jet area; single jet $A=1.19 \mathrm{in}^{2}$
$\mathrm{C}_{\mathrm{m}} \quad$ pitching moment coefficient; $C_{m}=P M /\left(T \cdot d_{\theta}\right)$
$C_{p} \quad$ pressure coefficient; $C_{p}=2 \Delta P(A) / T$
$d, d_{\theta} \quad$ equivalent nozzle diameter; single jet $d=1.23$ in, twin jet $d=1.74$ in
D equivalent model diameter (Fig. 11), plate diameter
h model distance to the ground plane
$\Delta L, \Delta L_{\infty} \quad$ jet induced lift, out of ground effect
NPR nozzle pressure ratio; NPR $=\mathrm{P}_{\text {jet }} / \mathrm{P}_{\mathrm{amb}}$
$P_{a m b}$ ambient pressure

\begin{tabular}{|c|c|}
\hline $\mathbf{P}_{\mathbf{i}}$ & local static pressure \\
\hline$P_{\text {jet }}$ & total pressure at jet exit \\
\hline$\Delta M$ & jet induced pitching moment \\
\hline$\Delta P$ & $\begin{array}{l}\text { local pressure difference; } \Delta P= \\
P_{i}-P_{a m b}\end{array}$ \\
\hline$S$ & model planform area \\
\hline$T$ & $\begin{array}{l}\text { thrust, } T=7.0 \mathrm{~A}\left(\mathrm{P}_{\mathrm{amb}}\right)[(\mathrm{NPR} 0.286)-1] \\
\text { NPR }<1.893\end{array}$ \\
\hline & $\begin{array}{l}T=A(P a m b)[(1.2679) N P R-1] \\
N P R>1.893\end{array}$ \\
\hline$T$ & jet temperature \\
\hline
\end{tabular}

Introduction

THE PROPULSION-INDUCED AERODYNAMICS of jet V/STOL (verticalshort takeoff and landing) aircraft hovering near the ground is a subject of investigation at NASA Ames Research Center. For a multiple-jet configuration in ground effect, a flow field is generated as shown in Fig. 1 . The hot jets impinge on the ground and form a wall jet that entrains surrounding air. This entrainment induces a low-pressure area on the lower surface of the aircraft called suckdown. Meanwhile, a fountain upwash is generated in the area between the jets, inducing a high-pressure area called fountain lift. The resultant of these two forces is the jet-induced litt. Hot gas ingestion is caused by the hot wall jet being drawn into the engine inlet.

In the 1950s and 1960s the effects of propulsioninduced aerodynamics were evaluated for a diverse set of V/STOL designs. However, a systematic variation of parameters consistent with current aircraft configurations is still needed to create a large data base for predicting the suckdown and hot gas ingestion on potential V/STOL designs. This parameter variation must include exhaust pressure ratios 
(NPR) as high as 6 and values of the ratio of wing area to jet area (S/A) of greater than 200. Also, data must be obtained on hot gas effects. Wyatt (1) described the first of these efforts to predict the suckdown. Most studies described in the literature, however, were force-and-moment tests on complete VISTOL configurations of NPR $\leq 2$ and $S / A \leq 100$. Pressure-distribution data that can improve understanding of the mechanisms involved is rarely available.

NASA Ames has been conducting a program to improve the methods for predicting the forces and moments as well as hot gas ingestion on V/STOL and STOVL fighter aircraft. This program includes CFD analysis and improved empirical methods for both in- and out-of-ground-effect conditions. As part of this program a data base is being created for a small-scale hover test apparatus that provides a systematic variation of parameters so that an improved empirical prediction procedure can be developed.

The first series of tests in this program has been completed. Details of this work can be found in the following references. Reference 2 presents the single-jet data obtained with a circular plate in both a small and a large testing room. These tests provided an evaluation of the adequacy of the facility and data for comparison with existing results in the literature. Reference 3 presents force, moment, and pressure data for two generic STOVL models. References 4 and 5 present the analyses of these data that have been completed to date, and an initial application of the results to an expanded prediction method. The present paper presents an overview of the results from Refs. 2, 3, and 4.

\section{Description of Tests}

\section{Large Room}

In order to evaluate the adequacy of the experimental setup and the test cell in which the bulk of the investigation was run, a special single-jet test was conducted in the high-bay area of the 40 -by 80-Foot Wind Tunnel (here termed "large room"). The hover test rig (Figs. 2 and 3) mounted in the large room consisted of an upward-directed jet (diameter $=1.23 \mathrm{in}$.) issuing through a hole in the center of a circular plate. High-pressure air was fed to a rectangular plenum chamber supplying the jet nozzle. The circular plate was mounted to a balance such that the nozzle and plenum chamber were non-metric, that is, the balance measured only induced aerodynamic forces on the circular plate.
For in-ground-effect studies an 8- by 8-tt plywood groundplane was used. This groundplane could be positioned vertically, thereby varying the simulated ground height between 1.6 and 32 jet diameters. The entire rig was installed in the high-bay area of the 40 - by 80 -Foot Wind Tunnel (Fig. 3 ) to assure negligible interference from the walls or ceiling. The nozzle conformed to the long-radius ASME contour and was equipped with three internal porous plates to provide good flow quality. Surveys of the jet exit flow contirmed a good-quality jet with a nearrectangular jet exit velocity distribution (2).

\section{Test Cell}

The main body of the experiment was conducted in a test cell much smaller than the large room described above but still typical laboratory size (Figs. 4 and 5). The hover test rig (Fig. 4) in the test cell was also different from that described above.

This rig consisted of downward-directed jets mounted on a steel frame structure with a vertically adjustable ground plane(8- by 8 -ft metal). The same plenum chamber, nozzle, and balance were used as were used in the large room, but this rig was equipped with two nozzles and plenum chambers when the generic STOVL models, described below, were used. When a circular plate was tested, one of the two nozzle-plenum assemblies was removed. The balance was centrally mounted between the nozzles, as shown. The test cell was $20 \mathrm{ft}$ wide by $15 \mathrm{ft}$ high by $28 \mathrm{ft}$ deep (Fig. 5). At one end of the room there was a roll-up door that was $16 \mathrm{ft}$ wide and $11 \mathrm{ft}$ high. Tests were conducted with this door both open and closed to study the effect of the removal of most of one wall.

\section{Models}

Two circular plates were tested (20- and 10 -in. diameter, thickness $=0.25 \mathrm{in}$.). The edge of each plate was chamfered as shown (Fig. 2) to provide a thin edge $(0.050$ in.). Also, there was a thin $(0.050$-in.) annular gap between the plate and the nozzle to ensure that force was not transmitted between them. Each plate was equipped with two rows of pressure taps on each side.

In addition, two flat-plate generic STOVL models were tested (Figs. 6 and 7). One of these models was an aspect-ratio-2.3 wing/body that was also tested as a body-alone configuration. The other was an aspect-ratio-1.1 delta wing. These models were constructed of 1/4-in.-thick aluminum with chamfered edges.

The wing/body model had a leading-edge-sweep angle of $49^{\circ}$ and a trailing-edge-sweep angle of 
$-8^{\circ}$. The ratio of planform area to jet area was 105 . The delta wing had a leading-edge-sweep angle of $71^{\circ}$ and a trailing-edge-sweep angle of $-8^{\circ}$. The ratio of planform area to jet area was 156 . The moment reference point for each model was 17 in. aft of the nose and $1 \mathrm{in}$. forward of the balance.

Surface pressure taps were installed on both the bottom and the top of each flat-plate model in several chordwise rows. The wing/body was equipped with 67 pressure taps and the delta wing with 78 . These pressure taps are distributed in 2-in. increments in the chordwise and spanwise directions except in the area between the jets (the fountain area), where they are distributed in 1-in. increments along the longitudinal axis.

\section{Instrumentation, Data System, Test Conditions}

A six-component balance was used to measure the lift loss on the plates and on the STOVL models. Additionally, a pressure transducer was used to monitor nozzle pressure ratio. Two pressure transducers (of maximum value 1 psig and 0.09 psig) were used separately on a 48-port scanning module. The 0.09-psig transducer was used to measure the small pressures on the 20 -in. plate when it was out of ground effect, and also served as a check on the reliability of the 1-psig transducer. There was also a pressure transducer to monitor ambient pressure. Thermocouples monitored the ambient temperature and the nozzle-exit air temperature. Signals from these transducers were appropriately conditioned and amplified.

Data were recorded and processed on-line on a HP 9000/200 minicomputer system. Lift loss was normalized by nozzle thrust for presentation of results. The thrust was obtained from an isentropic compressible flow equation (see Nomenclature) using the nozzle pressure ratio and temperatures.

Test conditions were NPR $=1$ to NPR $=6$ and jet temperatures from ambient to $700^{\circ} \mathrm{F}$.

\section{Results}

\section{Single Jet}

Out of Ground Effect - The lift loss induced out of ground effect in the large room and in the test cell are compared for the 20 -in. diameter plate in Fig. 8 for NPR $=1$ to 6 . An influence of room size can be seen. Litt loss was maximum with the test-cell door closed. It decreased when the test-cell door was opened, and decreased farther when the large room was used. These differences, however, are small (maximum $0.5 \%$ of thrust) compared to the magnitudes of the in-ground-effect lift loss. Since the effect is small, subsequent data are not corrected for the effect of the room size on out-ofground-effect litt loss. Unless noted otherwise, for the remainder of the data presented here the testcell door was kept open.

In Ground Effect - Results for both the 10- and 20-in. plates in the large room and in the test cell are presented in the form originally proposed by Wyatt (1) and are compared with his results in Fig. 9. The out-of-ground-effect lift results are subtracted from the in-ground-effect lift results, and the ground height is normalized by the plate diameter difference. The results collapse to a straight line (log-log plot) for the large-room data. For the testcell results the data are on a slightly different line for low ground height but exhibit the effect of the walls at greater height (above $W(D-d)=1.0$ ). These data are for a pressure ratio of 1.5 , which corresponds to the condition used to obtain the Wyatt data. The major significance of these results are that there are large differences from those of Wyatt.

Comparisons (4) were made between the present results and those of other investigations which confirmed the differences found with those of Wyatt. For example, Christiansen (6) conducted a largescale investigation using a $\mathrm{J}-97$ jet engine with a circular plate. At low ground heights, his results (Fig. 10) show considerably more suckdown than predicted by Wyatt and tend to be in better agreement with the present results. At the higher heights, his results are closer to Wyatt but are within $1 \%$ or less of the present results.

Other comparisons are available from the literature that involve non-circular models, rectangular plates, and aircraft-like planforms. Wyatt conducted a study using circular, rectangular, and triangular planforms and developed a method for comparing the results $(1,7)$. This method was evaluated in the present study using the 20 -in. diameter plate and the delta-wing model (Fig. 11). Planforms are compared on the basis of equivalent diameter according to Wyatt's method, using the equation shown. The circular-plate results are compared to results for the delta wing with the front jet only and with the rear jet only. For the rear jet only, the data agree well with the circular-plate results. The frontjet-only data are significantly different from the circular-plate data. These results confirm that the equivalent-diameter-planiorm comparison technique works well when the jet is near the centroid of the area. This has also been observed by other investigators in comparing the data from rectangular planforms with centrally located jets. 
The poor agreement for the case with the front jet alone suggested the need to modify the interpretation of some of the results that are found in the literature for wingbody configurations. Specifically, it is shown in Reference 4 that when the equivalent diameter of the wing/body configuration is based on the wing planform only and not on the wing/body planform, the data for the wing/body configurations are in better agreement with present results than with Wyatt's results. When the equivalent diameter is used, it can be seen (Fig. 12) that the present results are in better agreement with the results for the two sizes of rectangular plates studied by Stewart and Kuhn (8) than with the Wyatt results. Similarly, the present results are in good agreement (Fig. 13) with the circular-and rectangular-planform studies of Gentry and Margason (9).

It is concluded that there are serious anomalies in the results for hover ground effect. Further study is needed to reproduce the conditions of the Wyatt experiments and resolve the differences.

Pressure Ratlo - The results in Figs. 9-13 were obtained at a pressure ratio at or below 2 since this is the range that corresponded to the Wyatt results. It is shown in Fig. 14 that the effect of pressure ratio on induced lift is small up to pressure ratio of 4. A small reduction of slope was found between pressure ratios of 2 and 4, i.e., less suckdown at low ground height for pressure ratio of 4 compared to 2 .

\section{Twin Tandem Jet}

A major objective of the present program is to develop methods for predicting forces and moments on arbitrary STOVL and VISTOL configurations with various configurations of jet arrangements. As a first step toward this objective, the two configurations shown in Fig. 6 were studied. Each had the same twin-tandem-jet configuration and differed in planform, aspect ratio, and the ratio of wing to jet area. Much of the data in the literature is for area-ratio values of about 100 , whereas the values for configurations now being considered for supersonic STOVL aircraft can be in excess of 200 . The larger this ratio is, the larger is the magnitude of the induced forces that result from the additional surface area. The values for the two configurations shown in Fig. 6 are $S / A=105$ and 156.

Prediction Method Data - A method that has been widely used for the prediction of lift in ground effect is described in Ref. 10. This method is based on the correlation of available force data and works reasonably well for configurations similar to those in the data base from which it was developed. There is no method currently available for estimat- ing the pitching moments associated with the jet induced lift in ground effect. A new approach has been proposed by Kuhn (5) that is based on the pressure distribution and thereby allows the prediction of both lift and pitching moment. It is intended that sufficient data will be obtained in the present test program that such an empirical method can be validated for the configurations of the STOVL and VISTOL aircraft that are now being proposed. The results presented in this paper are a start in this process. Another paper to be presented in this session deals with the development of this new prediction method (11).

A typical surface pressure distribution obtained in the present study (Fig. 15) shows the suckdown and fountain regions that were shown schematically in Figure 1 . The positive pressure in the midregion between the jets results from the fountain. An additional suckdown region is found in each of the regions between the fountain and the fore and aft jets. This is the result of vortical flow between the downward-directed jet and the upward-directed fountain. It can be seen that this additional jet suckdown is greater for the aft jet than for the forward jet. This is due to the locally greater wingspan at this location. A suckdown region similar to that for single-jet suckdown is found forward and aft of each.jet.

The results for lift and moment for the three configurations tested (delta wing, wing/body, body alone) appears in Figure 16. It can be seen that the net suckdown forces and moments are substantially greater for the delta wing than for the wing/body configuration because of the approximately $50 \%$ greater ratio of wing area to jet area.

A concern in the development of a prediction method is the effect of jet pressure ratio and temperature. Most of the data in the literature are for a pressure ratio of approximately 2 , and ambient temperature-the typical values for the capability of most laboratories. These values are, however, substantially lower than the values for proposed future STOVL aircraft. It was noted above that the effect of pressure ratio for the circular plate results was small. It was also found (Fig. 17) that for the delta wing the effects of both pressure ratio and temperature are small up to the maximum values shown $\left(N P R=4, T=500^{\circ} \mathrm{F}\right.$ ).

Effect of LIDs - The effect of two configurations of simple lift improvement device (LID) configurations on induced lift is shown in Fig. 18. LIDs are intended to increase the lift of the fountain and to decrease the suckdown pressures. They are also . used to direct hot jet exhaust away from the engine 
inlets. It can be seen that the net suckdown has been substantially reduced by use of the LID.

\section{Concluding Remarks}

It has been found that the suckdown force on a circular disk with a central jet in ground effect is greater than that reported by Wyatt (which is the basis of the current commonly used prediction method). Other sets of data showed better agreement with the present data than with Wyatt's data. It is concluded that further tests should be performed to explain these differences.

The tests of the generic STOVL configurations were conducted to provide forces and pressures for a parametric variation of parameters so that an empirical prediction method could be developed. It has been shown that the present pressure distributions exhibit the known flow character of suckdown, fountain, and additional suckdown adjacent to the fountain. The effects of jet pressure ratio and temperature were found to be small for NPR values up to 4 and temperatures up to $500^{\circ} \mathrm{F}$. Lift improvement devices were shown to substantially reduce the net suckdown forces.

\section{References}

1. Wyatt, L. A., "Static Test of Ground Effect on Planforms Fitted With a Centrally-Located Round Lifting Jet." Ministry of Aviation, CP 749, June 1962.

2. Bellavia, D. C., Wardwell, D. A., Corsiglia, V. R., and Kuhn, R. E., "Forces and Pressures Induced on Circular Plates by a Single Lifting Jet in Ground Effect." NASA TM-102816, to be published.

3. Bellavia, D. C., Wardwell, D. A., Corsiglia, V. R., and Kuhn, R. E., "Suckdown, Fountain Litt, and Pressures Induced on Several Tan dem Jet VTOL Configurations." NASA TM-102817, to be published.

4. Kuhn, R. E., Bellavia, D. C., Wardwell, D. A., and Corsiglia, V. R., "On the Anomalies in Single-Jet Hover Suckdown Data "NASA TM-102261, to be published.

5. Kuhn, R. E., Bellavia, D. C., Corsiglia, V. R., and Wardwell, D. A., "On the Estimation of JetInduced Fountain Lift and Additional Suckdown in Hover for Two-Jet Configurations." NASA TM-102268, to be published.

6. Christiansen, R. S. "A Large Scale Investigation of VSTOL Ground Effects." AIAA Paper 0366, Jan. 1984.

7. Wyatt, L. A. "Tests On the Loss of Vertical Jet Thrust Due to Ground Effect on Two Simple VTOL Planforms, with Particular Reference to the Short SCI Aircraft." Aeronautical Research Council Reports and Memoranda No. 3313, May 1958.

8. Stewart, V. R. and Kuhn, R. E. "A Method for Estimating The Propulsion Induced Aerodynamic Characteristics of STOL Aircraft in Ground Effect." Naval Air Development Center Report No. NADC-80226-60, August 1983.

9. Gentry, G. L. and Margason, R. J. "JetInduced Lift Losses on VTOL Configurations Hovering In and Out of Ground Effect." NASA TN D-3166, February 1966.

10. Kuhn, R. E. "An Engineering Method for Estimating the Induced Lift on VISTOL Aircraft Hovering In and Out of Ground Effect." NADC-80246-60, January 1981.

11. Wardwell, D. A., and Kuhn, R. E., "Summary of Prediction Techniques For Jet-Induced Effects In Hover On STOVL Aircraft." NASA TM-102818, to be published. 


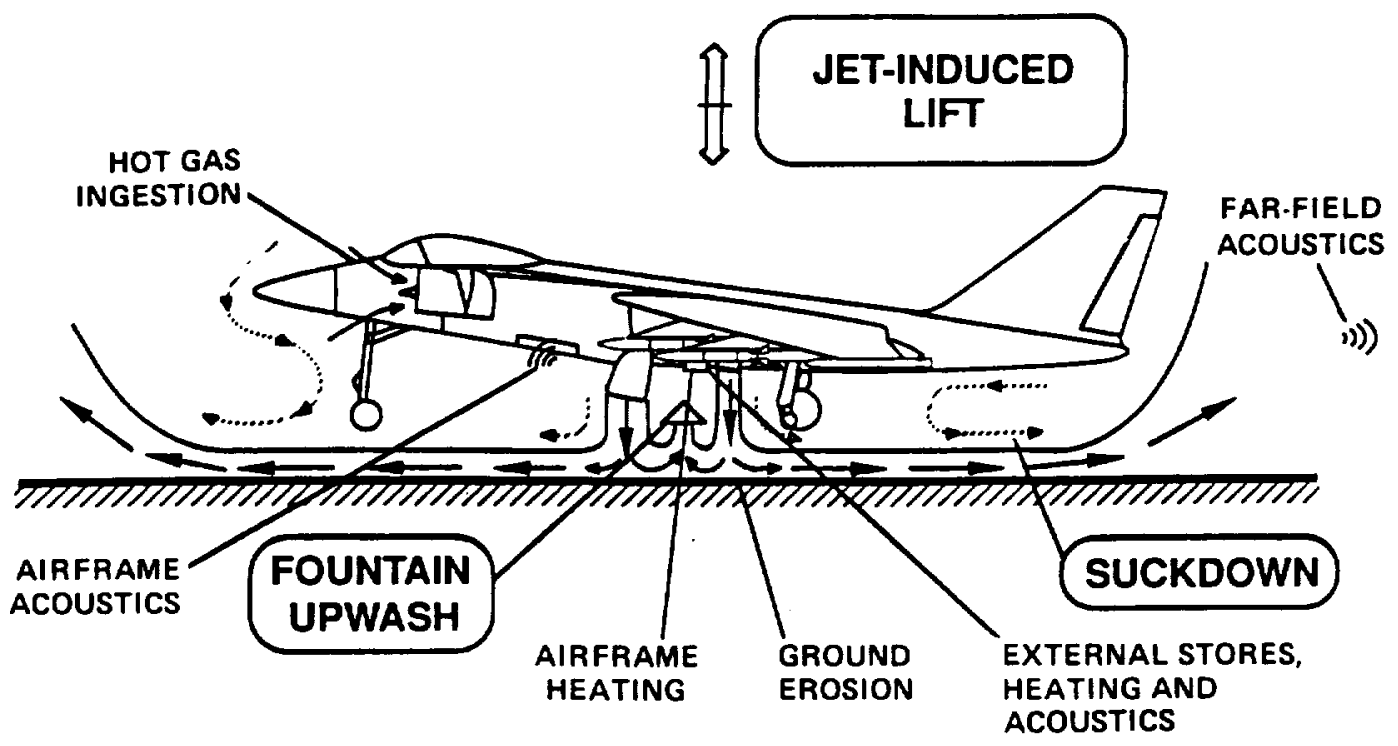

Fig. 1. Research topics associated with the flow field of a STOVL aircraft hovering in ground effect.

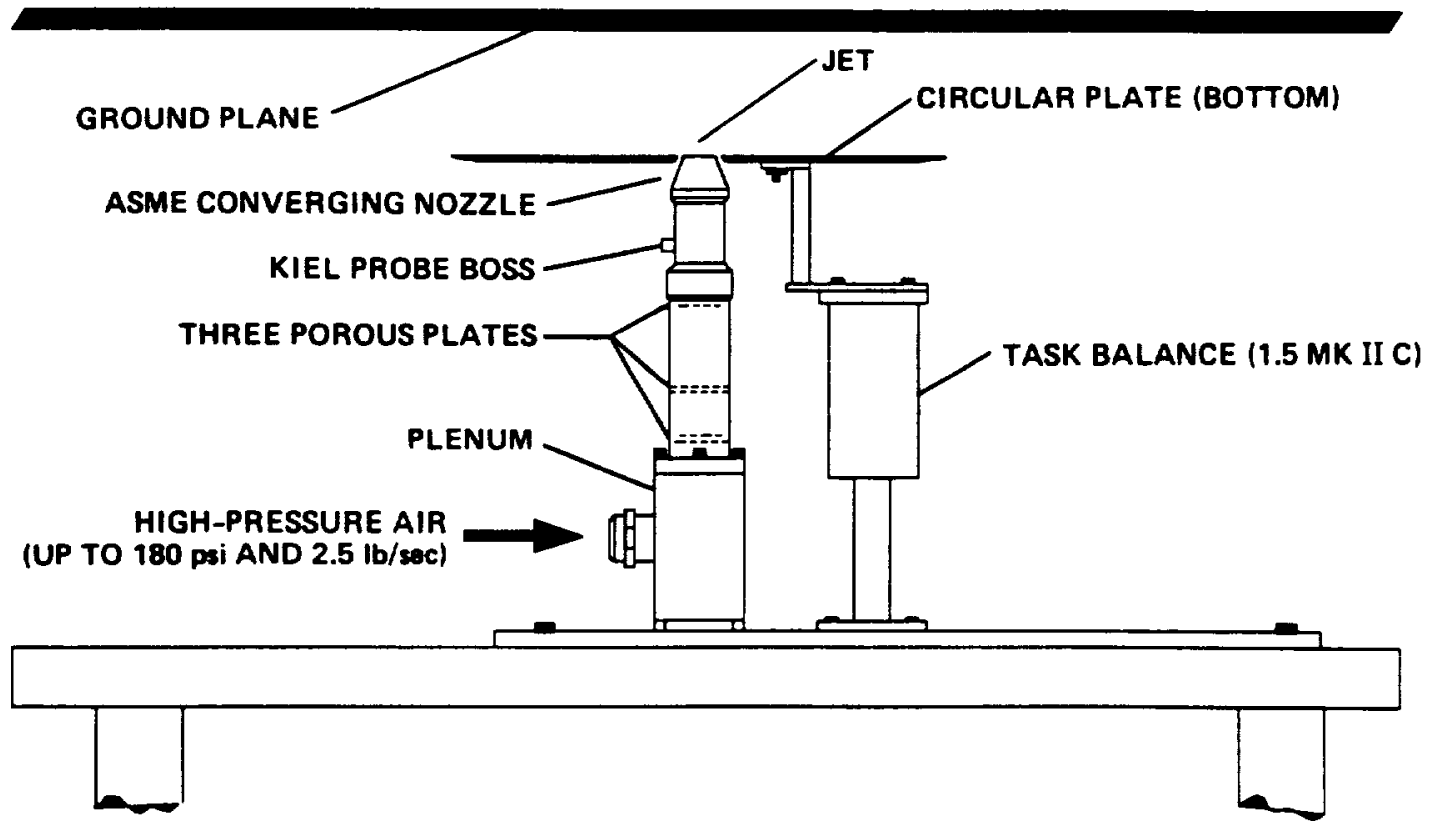

Fig. 2. Test setup, large room, located in high-bay area of 40 - by 80 -foot wind tunnel. 


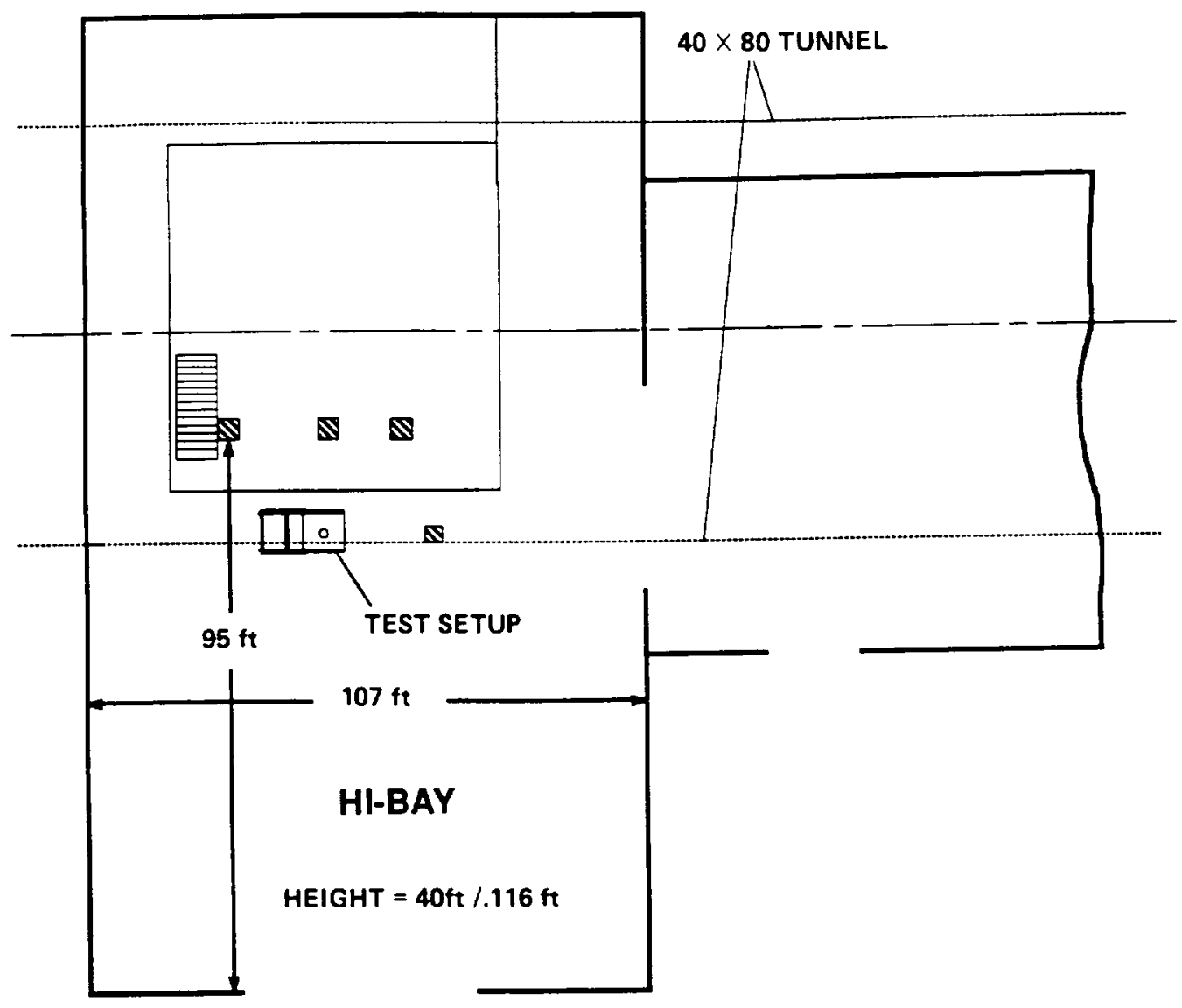

Fig. 3. Location of test setup (large room) relative to walls and ceiling.

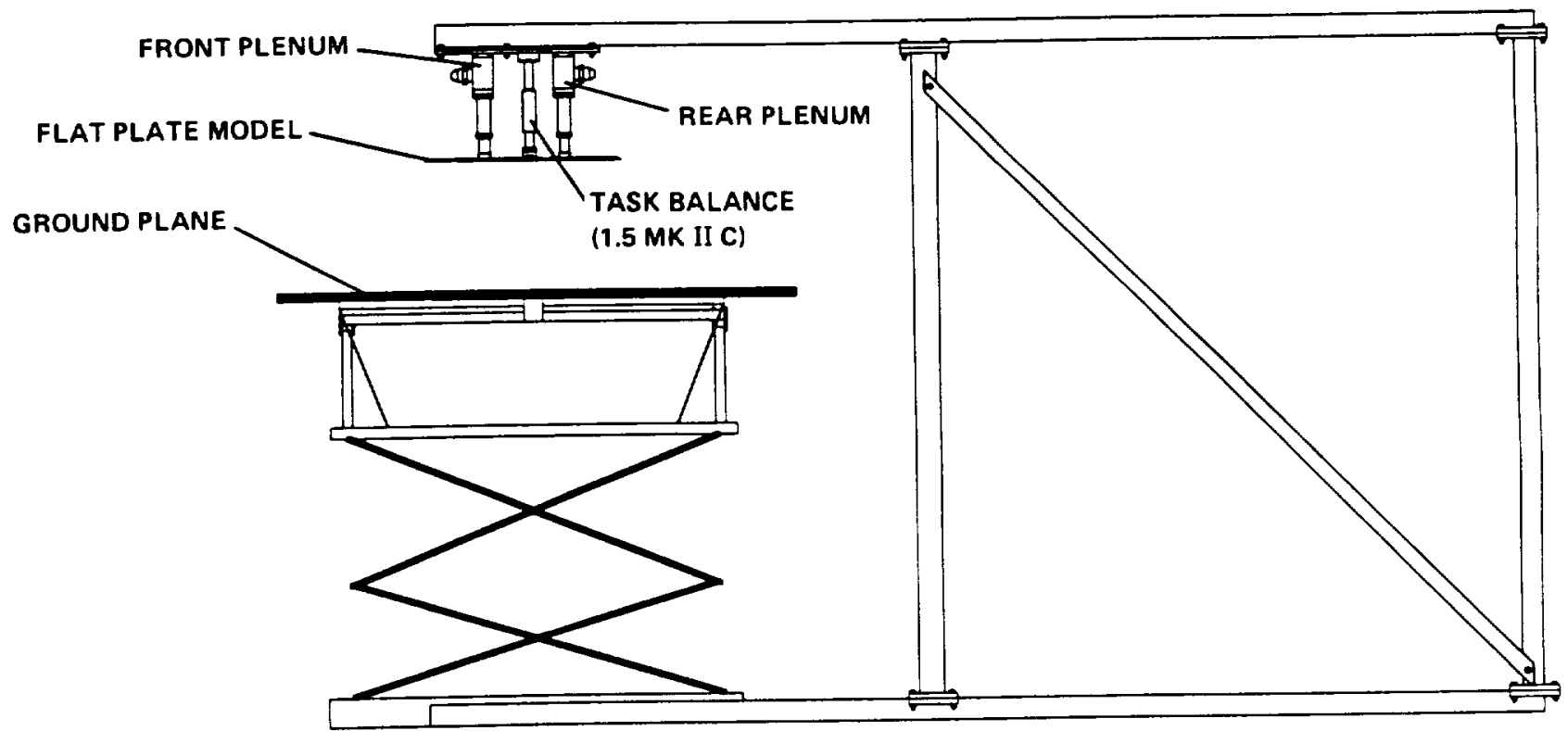

Fig. 4. Test setup, test cell, located at Lockheed Aircraft Corporation Rye Canyon Facility. 


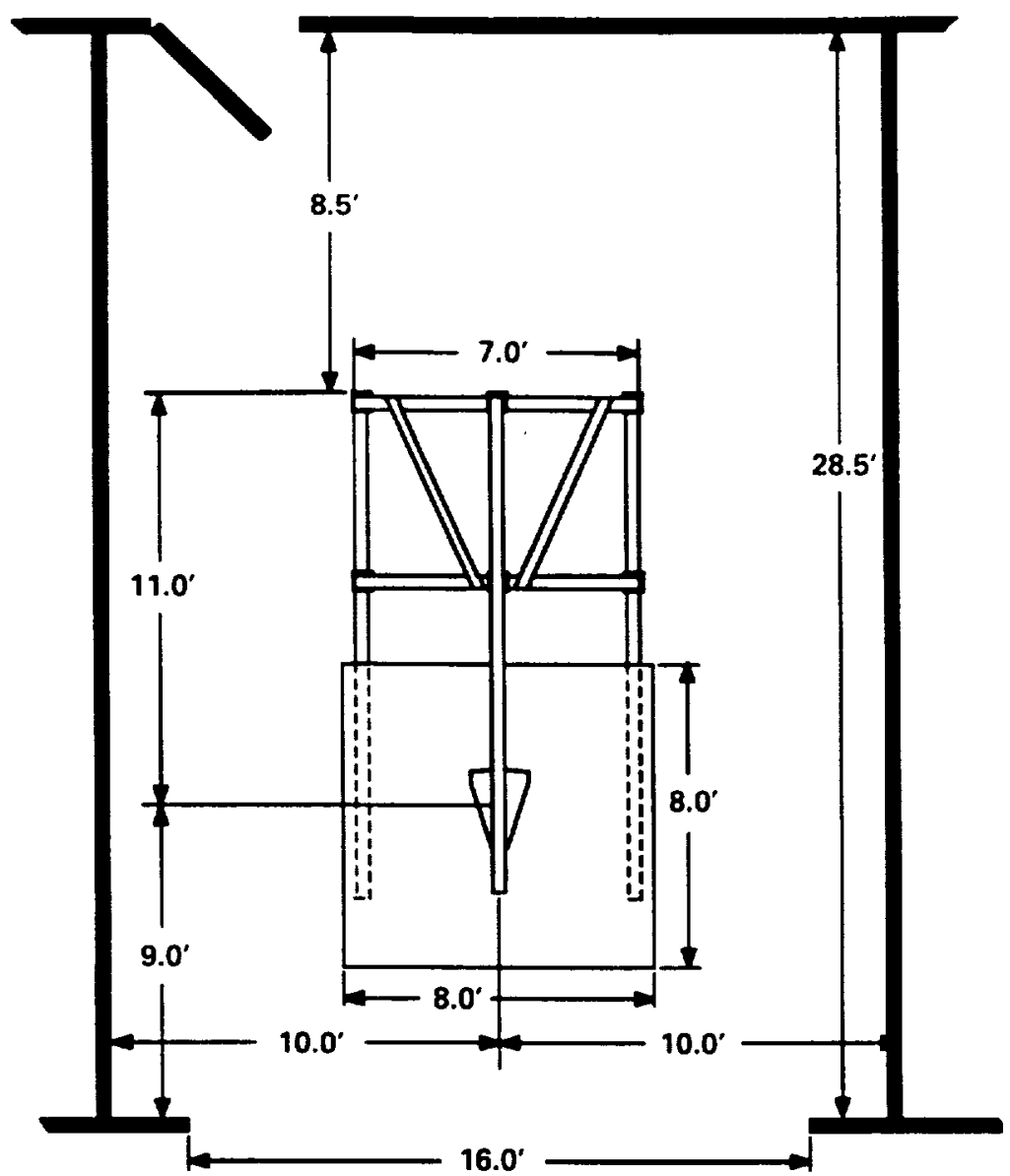

FRONT VIEW

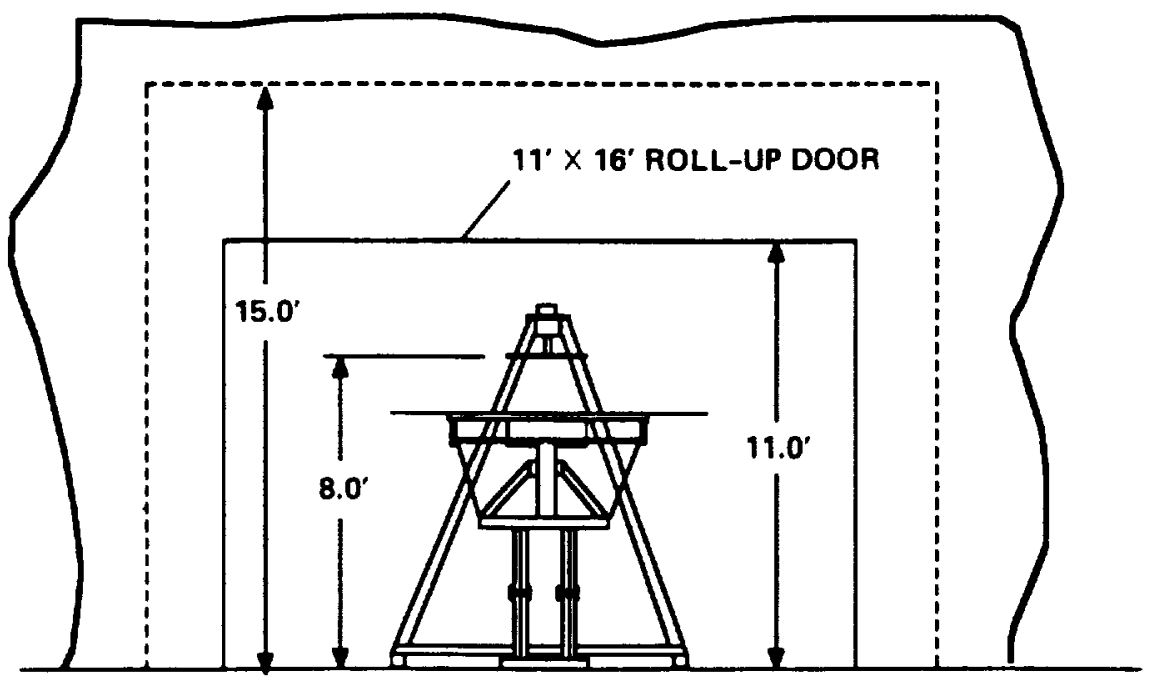

Fig. 5. Location of test setup (test cell) relative to walls and ceiling. 


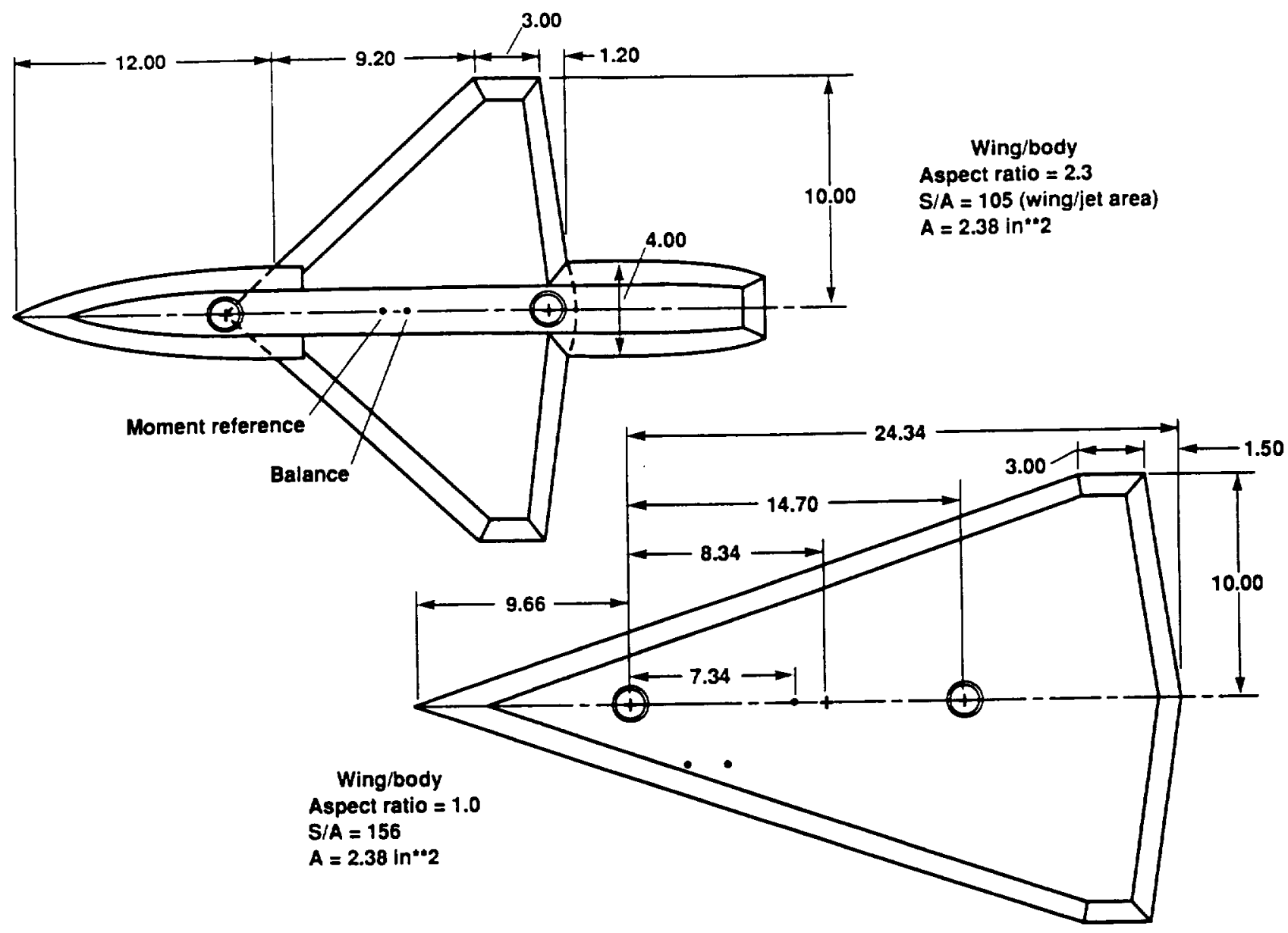

Fig. 6. Flat-plate generic STOVL models tested in the test cell.

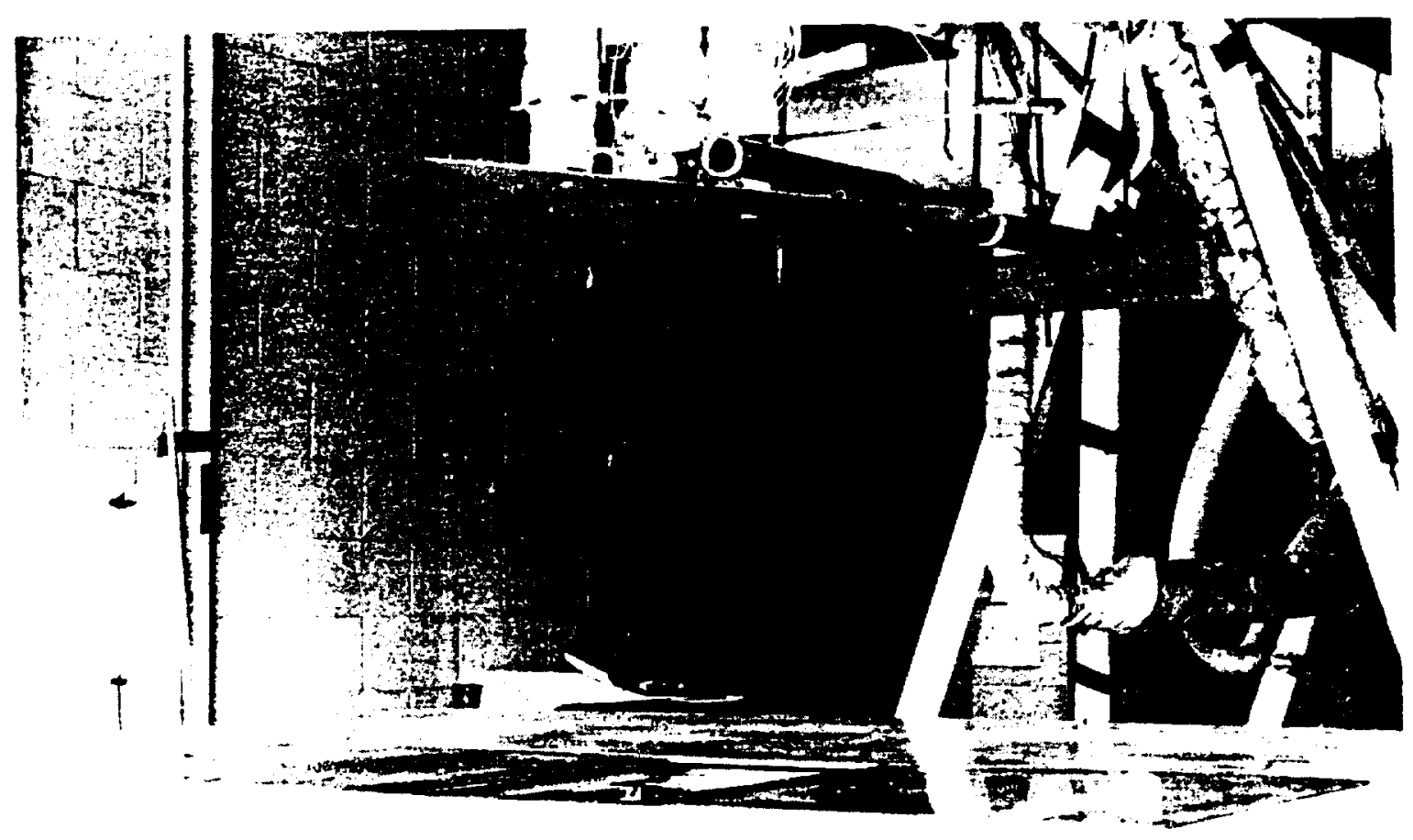

Fig. 7. Delta wing model installed in the test cell. 


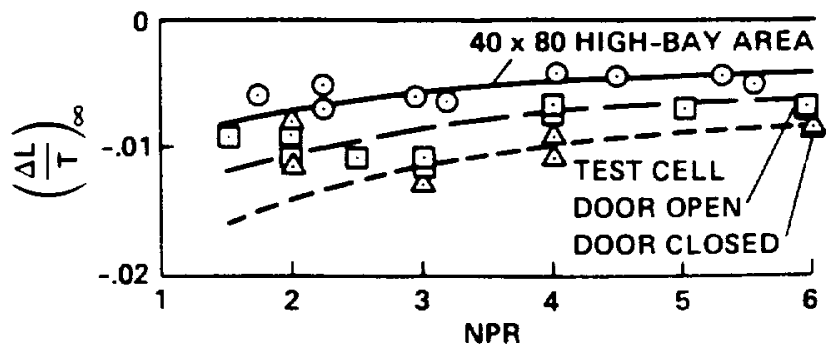

Fig. 8. Lith loss out of ground effect, 20-in. plate model.

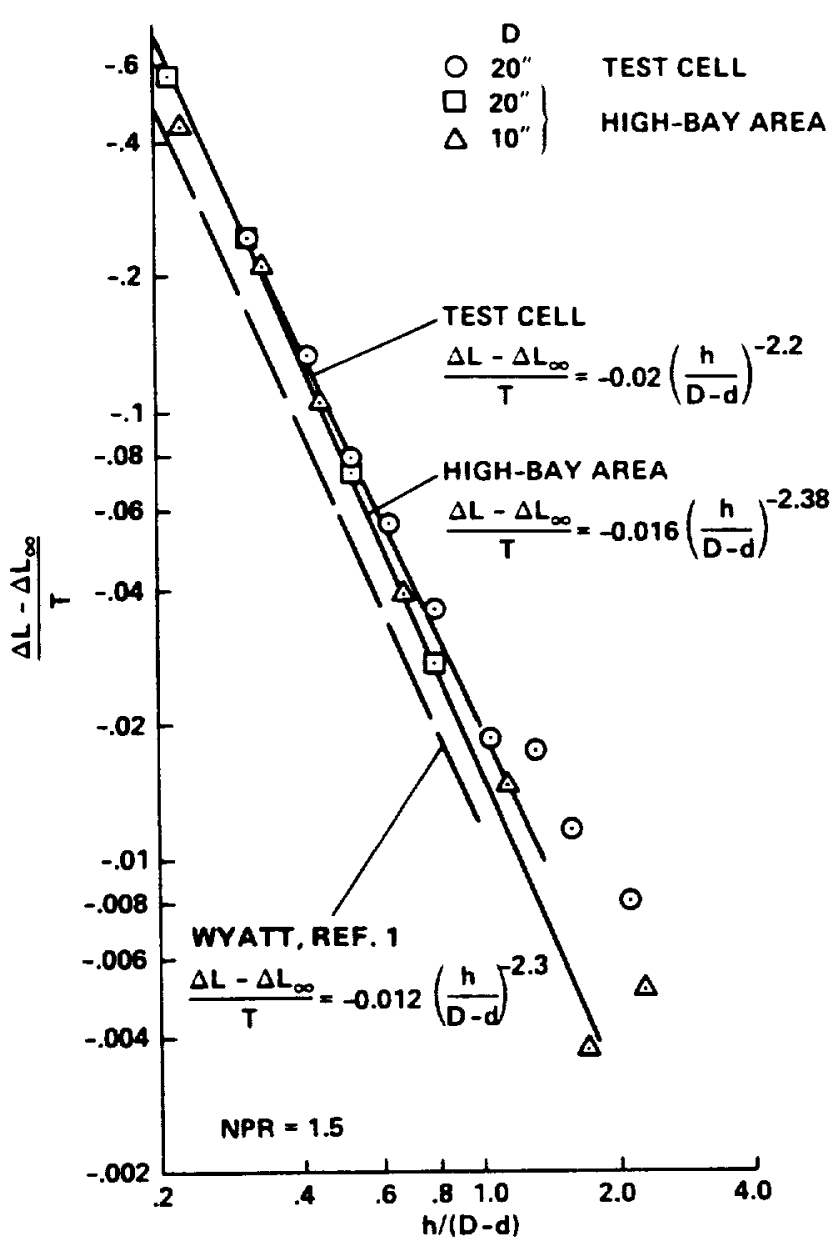

Fig. 9. Lift loss in ground effect, comparison with the results of Wyatt.

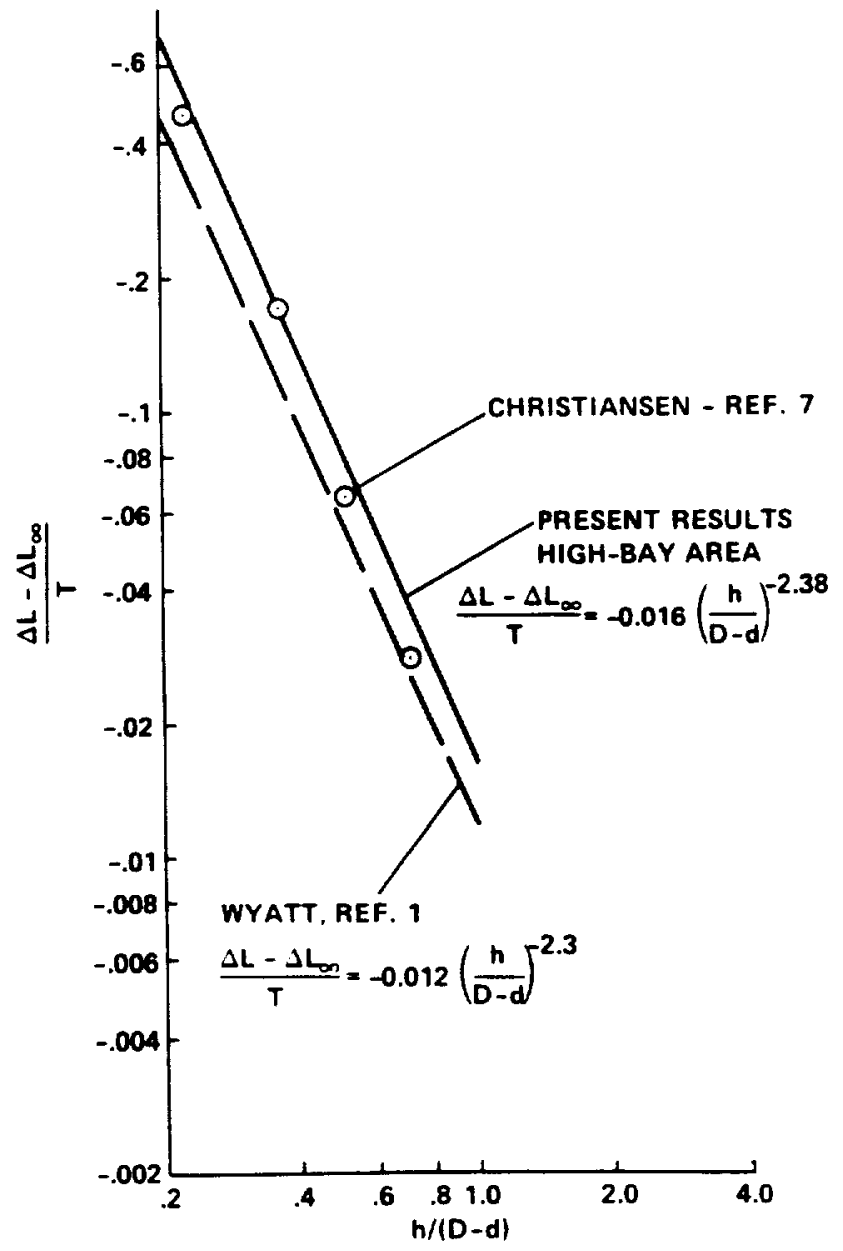

Fig. 10. Lift loss in ground effect, comparison with the results of Christiansen. 


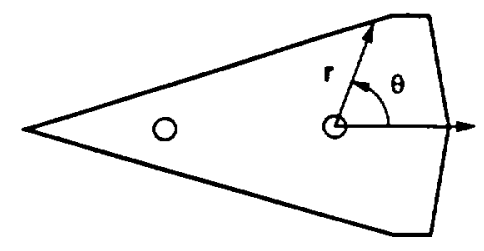

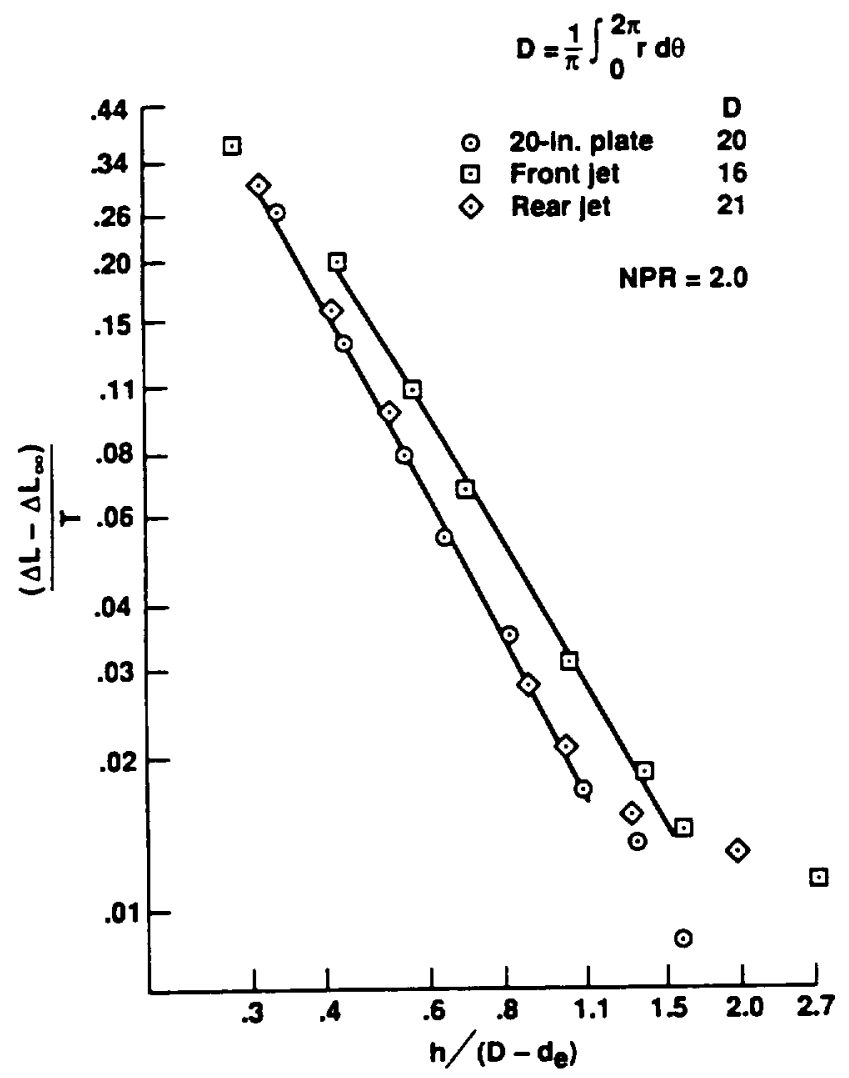

Fig. 11. Effect of planform/jet location on lift loss using Wyatt's definition of equivalent diameter.

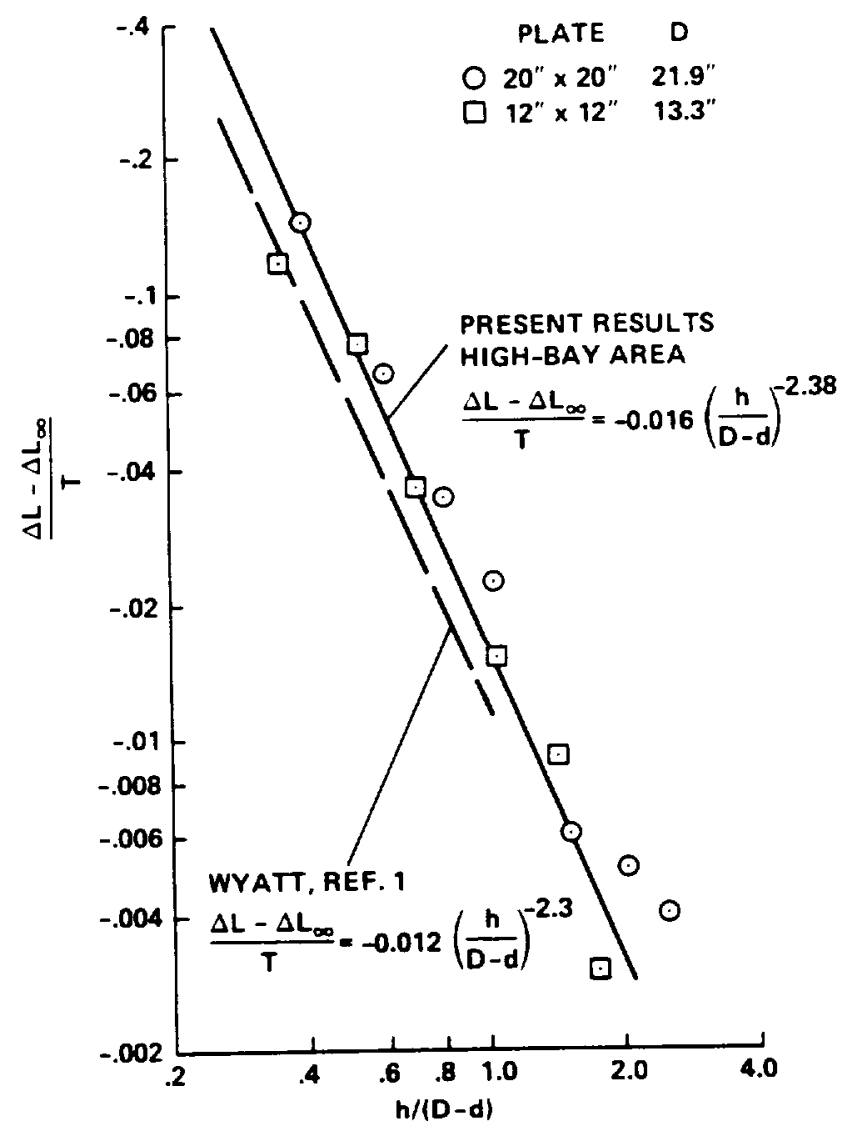

Fig. 12. Lift loss in ground effect, comparison with the results of Stewart and Kuhn. 


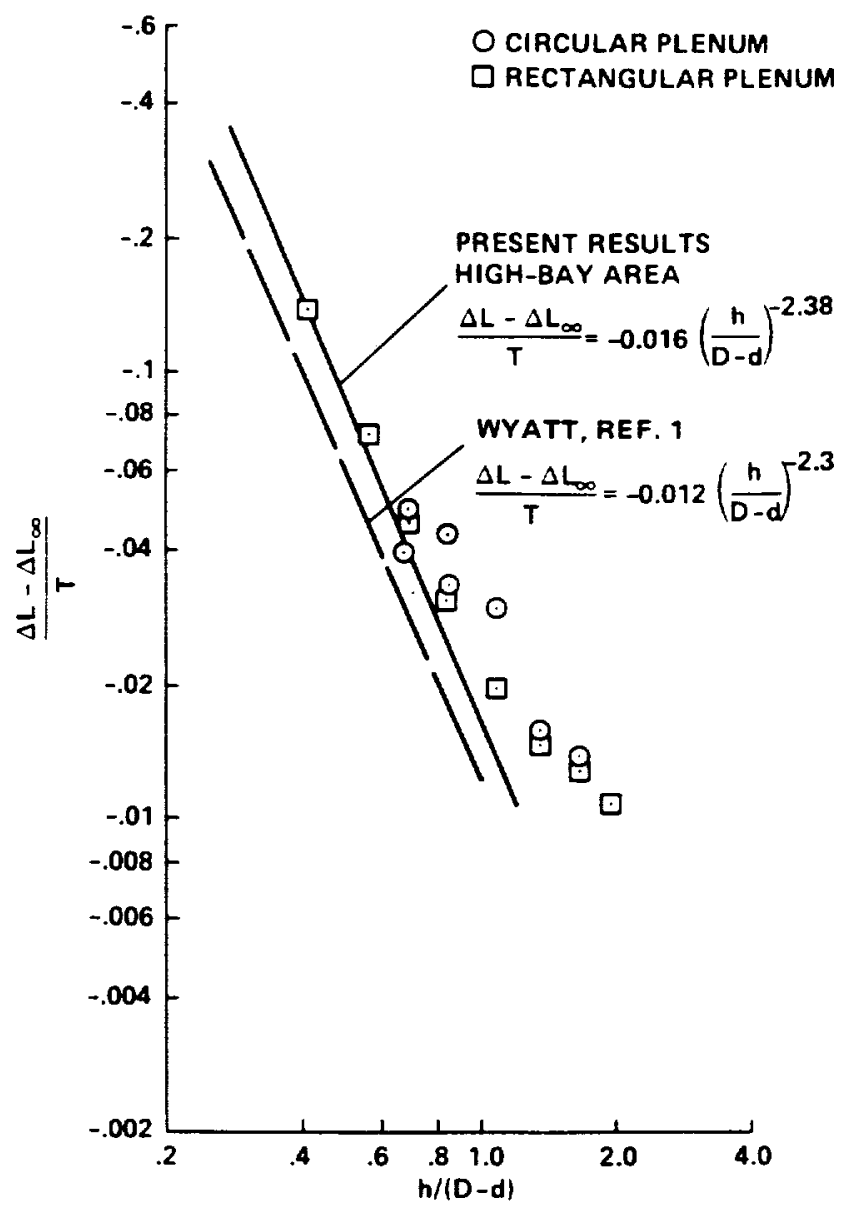

Fig. 13. Lift loss in ground effect, comparison with the results of Gentry and Margason.

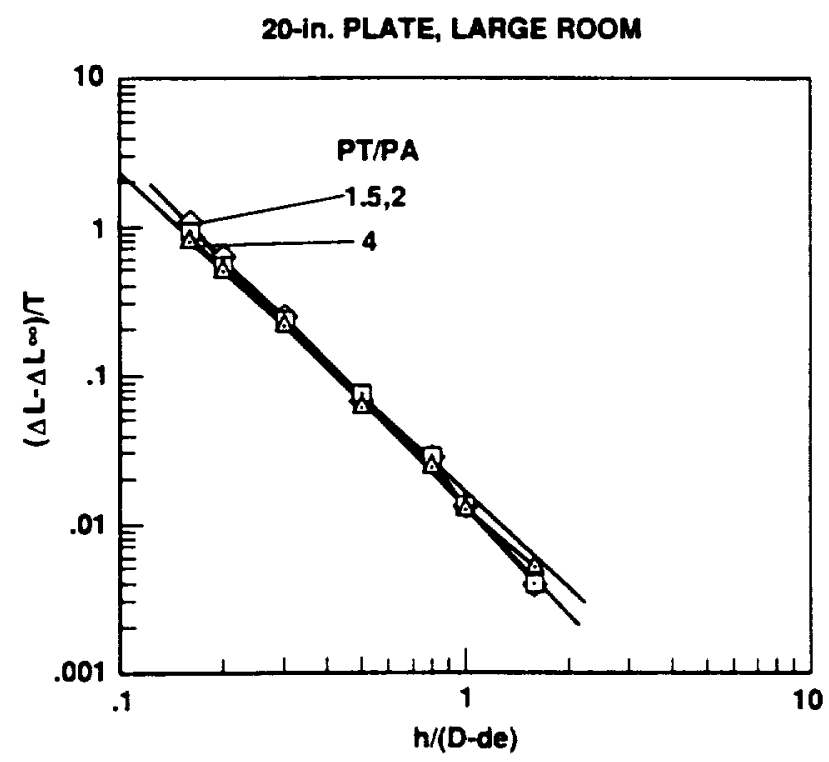

Fig. 14. Effect of jet pressure ratio on lift loss, 20 -in. plate, large room.

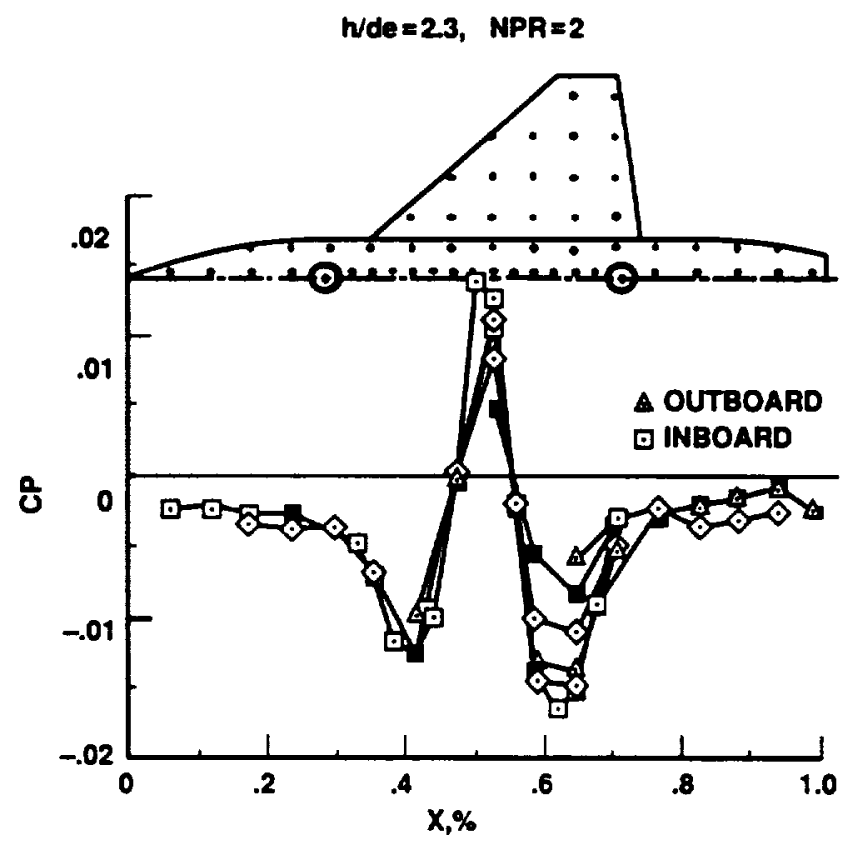

Fig. 15. Chordwise pressure distributions, wing/body configuration, $\mathrm{h} / \mathrm{d}_{\theta}=2.3, \mathrm{NPR}=2$. 

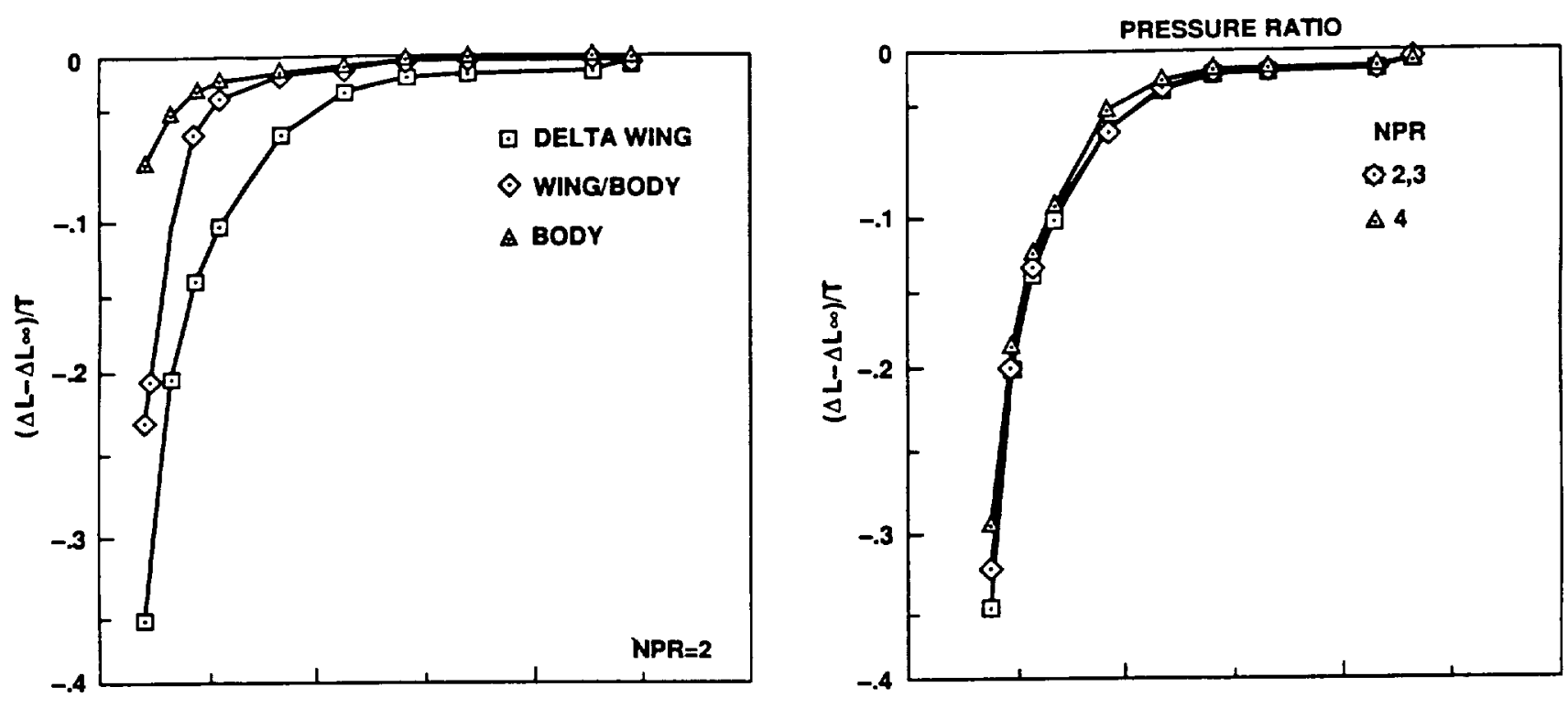

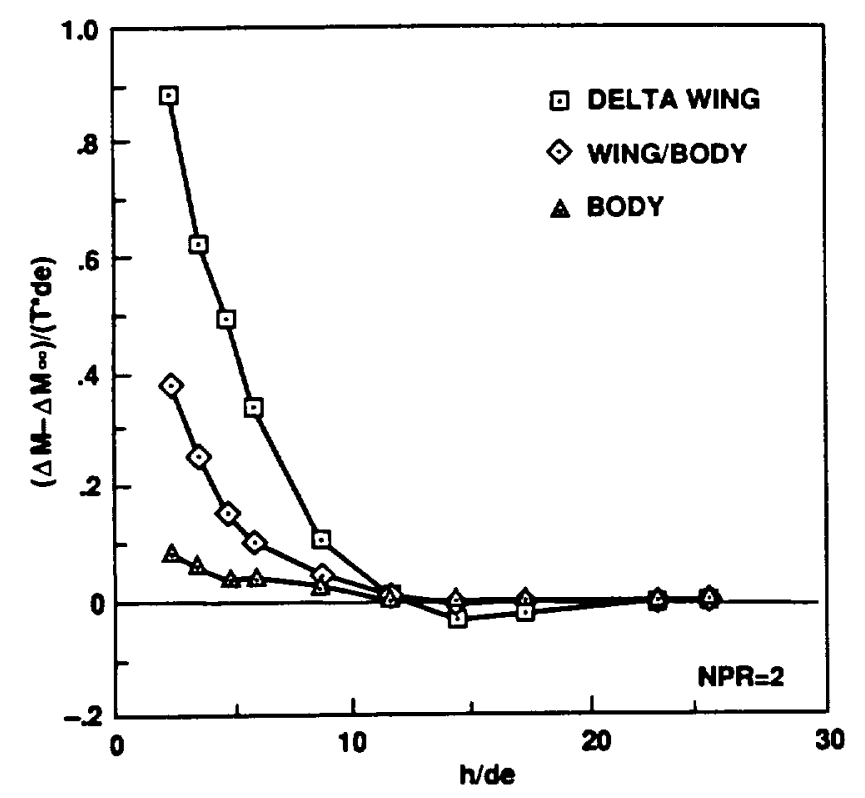

Fig. 16. Lift loss and moment in ground effect, $\mathrm{NPR}=2$.

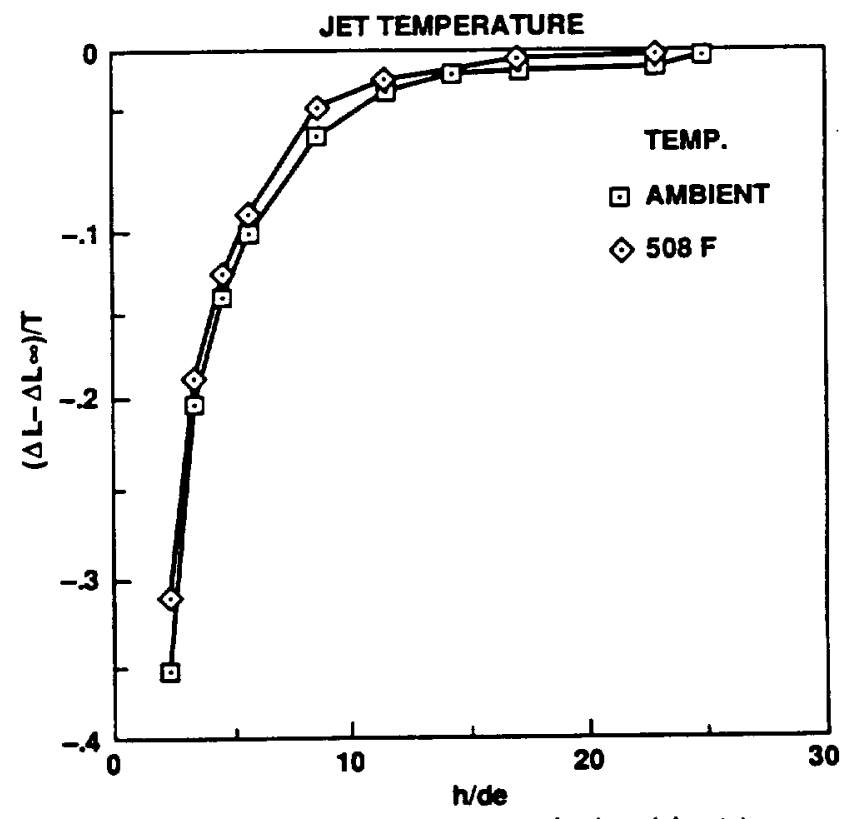

Fig. 17. Effect of jet pressure ratio (ambient temperature) and temperature (NPR $=2$ ) on litt loss, delta wing.

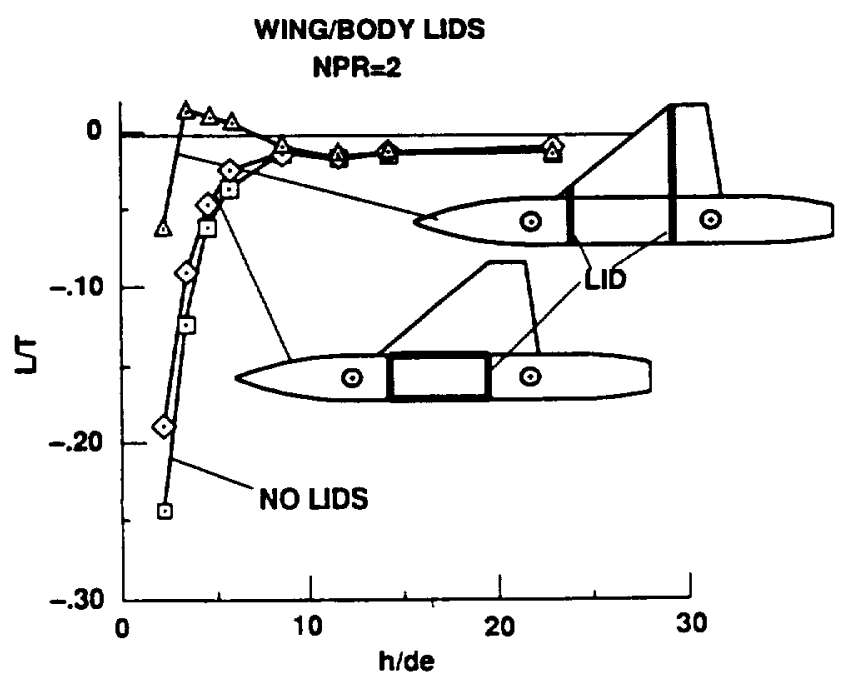

Fig. 18. Effect of LIDs, wingbody configuration, NPR $=2$. 


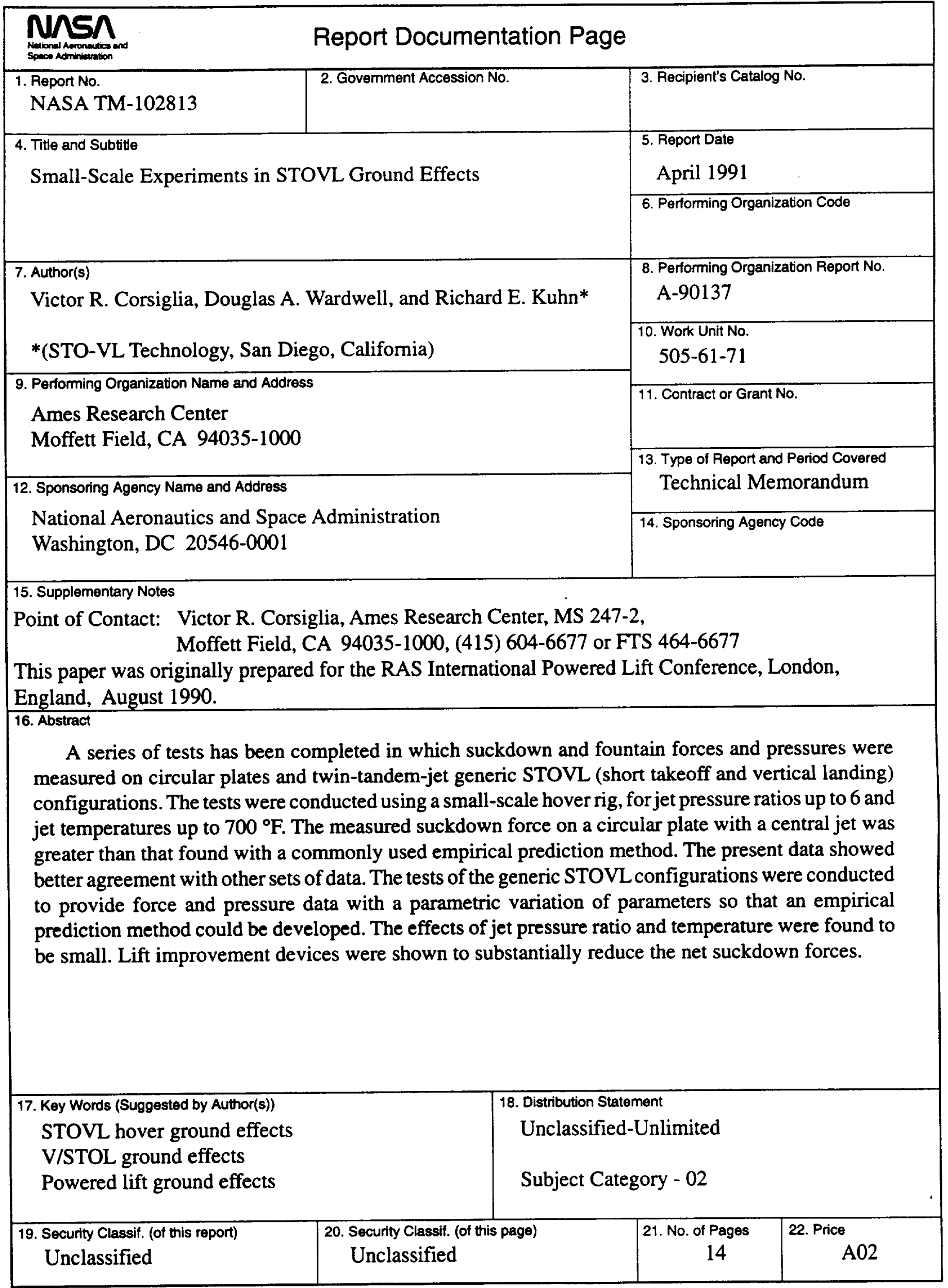

